\title{
28 Research Suare \\ Outcomes of Assisted Reproductive Technology in Women Infected with the Hepatitis B Virus
}

\section{Yimin Zhu ( $\nabla$ zhuyim@zju.edu.cn )}

Zhejiang University School of Medicine Women's Hospital https://orcid.org/0000-0002-9667-3677

\section{Xiaoling Hu}

Zhejiang University School of Medicine

\section{Shan Wan}

Zhejiang University School of Medicine

\section{Yunwen Chen}

Zhejiang University School of Medicine

\section{Xia Meng}

Zhejiang university

\section{Minyue Tang}

Zhejiang University School of Medicine

\section{Yanling Fu}

Zhejiang University School of Medicine

\section{Huanmiao Yan}

zhejiang university

Aixia Liu

Zhejiang University School of Medicine

\section{Xijing Chen}

Zhejiang University School of Medicine

\section{Yongchao Lu}

Zhejiang University School of Medicine

\section{Research article}

Keywords: Hepatitis B infection, women, assisted reproductive technology, live birth rate, ovarian responses

Posted Date: December 1st, 2020

DOl: https://doi.org/10.21203/rs.3.rs-114319/v1

License: (1) (1) This work is licensed under a Creative Commons Attribution 4.0 International License. Read Full License 
Page 2/16 


\section{Abstract}

Objectives: To investigate whether women infected with the hepatitis B virus affects the outcomes of assisted reproductive technology (ART).

Methods $₫ A$ total of $1542 \mathrm{HBV}$ infected women, and the same number of non-infected age-matched women undergoing fresh ART treatments. All male partners were without any history of HBV infection. Three groups were defined: HBV-positive, HBeAg/preS1-positive, and HBV-negative. Pregnancy outcomes were evaluated and compared using multivariate logistic regression analysis to control for confounding factors.

Results: No difference was observed in the live birth rate among couples according to HBV status; that is, women were $\mathrm{HBsAg}$ - or $\mathrm{HBeAg} /$ preS1-seropositive, or both partners were HBsAg-seronegative $35.29 \%$, $32.79 \%$, and $34.27 \%$, respectively; $P<0.05$ ). After multivariate modeling to adjust for the possible confounding variables, the live birth rate still did not differ significantly between the HBV-positive group or the HBeAg/preS1-positive group and the HBV-negative group (adjusted OR 1.11, 95\% Cl 0.93-1.32 and adjusted OR 1.02, 95\% $\mathrm{Cl} 0.83-1.25$, respectively). Furthermore, no differences were found in clinical pregnancy rate, miscarriage rate, birth weight, low birth weight rate, preterm rate or ovarian responses among the three groups. The incidence of secondary infertility and tubal factor infertility in women who were HBsAg- or HBeAg/preS1-seropositive was significantly higher than that in women without HBV infection.

Conclusions: HBV infection in women was associated with a higher risk of secondary infertility and tubal factor infertility, but has no significant impact on pregnancy outcomes and ovarian responses in HBsAgseropositive women as compared with HBsAg-seronegative women, irrespective of their serum HBeAg and preS1 status.

\section{Introduction}

Hepatitis B virus (HBV) infection remains a serious global public health problem despite effective HBV vaccines having been available for several decades [1]. According to the most recent World Health Organization (WHO) estimation, approximately 257 million individuals are living with chronic hepatitis B infection; adults chronically infected include 65 million women of childbearing age [2]. China, in particular, is one of the highest endemic areas for HBV infection, with one-third of chronic HBV carriers being Chinese [3]. Since a spontaneous pregnancy in patients with HBV infection is accepted, there is no reason to advise against in vitro fertilization (IVF) treatment in chronic HBV carriers [4]. Although standard screening of couples seeking IVF includes testing for HBV infection by serological analysis of hepatitis B surface antigen (HBsAg), HBV infection in either partner is not a contraindication for IVF treatment [5].

Chronic HBV infection is associated with progressive, significant impairment of the immune response and enhancement of immune tolerance [6]. Patients with HBV infection have a higher incidence of 
infertility than those who are not infected [7]. Previous studies have revealed that men with chronic HBV infection have impaired sperm quality [8,9], which results in a reduced fertilization rate [8-10]. HBV DNA has been identified in the oocytes and embryos of HBsAg-positive women $[11,12]$. However, only a few studies, with inconsistent results, have evaluated the effect of chronic HBV infection in women on the outcomes of assisted reproductive treatment $[10,13,14]$ or pregnancy [15-17].

The effect of HBV on the outcomes of IVF or intracytoplasmic sperm injection (ICSI) remains controversial. The objective of the present case-controlled retrospective study was to assess the impact of hepatitis B virus infection in women on the outcomes of couples undergoing assisted reproductive technology (ART).

\section{Materials And Methods}

This was a retrospective cohort study of IVF/ICSI and embryo transfer (ET) cycles performed in couples at the assisted reproductive unit of the Women's Hospital, Zhejiang University School of Medicine from 2009 to 2015. The present study was approved by the Ethics Committee of the Women's Hospital, Zhejiang University School of Medicine (Approval number: IRB-20190039-R). Serological screening for hepatitis $B$ is performed as part of the routine evaluation of couples undergoing ART in China and includes the following tests: HBsAg and its antibodies (anti-HBs); hepatitis B e-antigen (HBeAg) and its antibodies (anti-HBe); and antibodies against the hepatitis B c-antigen (anti-HBc). If the HBsAg was seropositive, preS1 was further examined at our center. $\operatorname{HBeAg}[18,19]$ and preS1 $[20,21]$ are serum markers of active HBV replication, indicating a high HBV DNA load. To evaluate whether the status of viral replication affected the IVF/ICSI outcomes, we compared the outcomes of HBeAg/preS1seropositive women with those of the controls. For each HBsAg-seropositive cycle, one HBV-seronegative control cycle was randomly age matched (Fig. 1). All male partners either lacked any history of HBV infection or had been vaccinated. Based on hepatitis laboratory test results, the patients were categorized into the following three groups:

i. HBV-positive group: women were HBsAg-seropositive, irrespective of the serum status of $\mathrm{HBeAg}$ and pres1.

ii. HBeAg/preS1-positive group: women were HBsAg-seropositive and HBeAg- and/or preS1seropositive.

iii. HBV-negative group: women were without any history of HBV infection or had been vaccinated.

None of the patients were diagnosed with acute hepatitis or received any antiviral treatment for fertility. The HBsAg-seropositive women had chronic infection with normal liver enzyme levels. Women undergoing IVF for preimplantation genetic diagnosis; a history of recurrent spontaneous abortion; diabetes mellitus; an autoimmune disease; congenital defects (related to the reproductive organs); longterm drug use and/or toxin or radiation exposure; cigarette, alcohol or caffeine consumption; and any couples who were seropositive for hepatitis $\mathrm{C}$ virus (HCV) and/or human immunodeficiency virus (HIV) were excluded from the present study. 
The IVF/ICSI treatment information retrieved from the database included the following data: age; body mass index (BMI); HBV serostatus; type of infertility (primary or secondary); cause(s) of infertility categorized into tubal, anovulation, polycystic ovarian syndrome, endometriosis, male, unexplained and mixed factors; ovarian reserve assessment (basic FSH); number of previous cycles; and outcomes derived from controlled ovarian stimulation, including the duration and total dose of gonadotropin treatment, peak estradiol $\left(E_{2}\right)$ level, number of oocytes retrieved, number of fertilized oocytes, number of embryos transferred, pregnancy rate, live birth rate, birth weight and gestational age.

\section{Treatment protocols}

All eligible participants underwent IVF/ICSI ET using 1 of 4 conventional protocols: long, short, antagonist, and ultra-long protocol, which have been previously described [22, 23]. Selection of the stimulation protocol was based on patient characteristics or response during previous cycles. Oocyte retrieval was carried out 34 - 36 hours after hCG injection. Insemination was performed using standard IVF or ICSI procedures according to treatment indications. ET was performed 2 or 3 days after fertilization. One to three of the best embryos were selected for transfer according to the Code of Practice for Assisted Reproductive Technology developed by the Ministry of Health of the People's Republic of China. Cleavage embryos were defined as good quality (grade I or II) [24]. Supernumerary embryos were frozen for subsequent transfer. Luteal support involved $60 \mathrm{mg}$ intramuscular progesterone in oil administered from the day of oocyte retrieval to the 8th week of pregnancy. All fresh embryos were cryopreserved if the patient had an increased risk of ovarian hyperstimulation, fluid in the cavity, unfavorable endometrium, hydrosalpinx or fever. ET was cancelled when no embryo was available.

\section{Outcome measures}

The primary outcome variables were the pregnancy outcomes of ART, including the live birth rate (the birth of at least one living child beyond 28 weeks of gestation per ET cycle); implantation rate (number of gestational sacs per number of embryos transferred); clinical pregnancy (at least one gestational sac detected by ultrasound 5 weeks after the ET); miscarriage (clinical intrauterine gestation resulting in pregnancy loss or abortion < 28 weeks); low birth weight (a weight of less than 2,500 g at birth); and preterm birth (delivery between 28 and 37 completed weeks of gestation). Gestational age was calculated based on the date of ET. Secondary outcomes were the number of oocytes retrieved and the twopronuclear fertilization rate (number of confirmed two-pronuclear zygotes per number of oocytes retrieved).

\section{Statistical analysis}

Baseline and cycle characteristics were analyzed by ANOVA and Pearson's chi-square test as appropriate. Data are presented as a percentage or the mean \pm standard deviation. Pregnancy outcomes were compared using multivariate logistic regression analysis adjusted for confounding factors, including the type of infertility, causes of infertility, basic $\mathrm{E}_{2}$ level, peak $\mathrm{E}_{2}$ level, and HBV infection status. Two-sided $P$ 
values of $<0.05$ were considered as statistically significant. SPSS version 18 (IBM SPSS, USA) was used for data analysis.

\section{Results}

The data analysis included 3,084 women: 1,542 were HBsAg-seropositive, 970 of which were seropositive for HBsAg and HBeAg/preS1, and the other 1,542 were age-matched women with no history of HBV infection (Fig. 1).

\section{Comparison of baseline characteristics}

Patient and cycle characteristics in the HBV-seropositive, HBeAg/preS1-seropositive and HBVseronegative groups are shown in Table 1. The age of the women and their husbands, $\mathrm{BMI}$, and duration of infertility were similar among the three groups. The HBV-and HBeAg/preS1-positive groups had similar basic FSH levels, which were much higher than those in the HBV-negative group. Women who were HBVor HBeAg/preS1-seropositive were more likely to have secondary infertility and tubal factor infertility than those in the control group (59.66\%,58.76\%, and 53.44\%, respectively, $P<0.01$ and $57.26 \%, 57.01 \%$, and $52.14 \%$, respectively, $P<0.01)$. HBV- and HBeAg/preS1-positive groups had lower incidences of endometriosis $(P<0.01)$ and unexplained infertility $(P<0.01)$ as compared with the control group. 
Table 1

Baseline characteristics of infertility patients according to the hepatitis B virus status of the women

\begin{tabular}{|c|c|c|c|}
\hline Group & $\begin{array}{l}\text { HBV-positive } \\
(n=1542)\end{array}$ & $\begin{array}{l}\text { HBeAg/pres1-positive } \\
(n=970)\end{array}$ & $\begin{array}{l}\text { HBV-negative } \\
(n=1542)\end{array}$ \\
\hline Female age (years) & $31.7 \pm 4.6$ & $31.4 \pm 4.6$ & $31.7 \pm 4.5$ \\
\hline Male age (years) & $33.6 \pm 5.3$ & $33.5 \pm 5.4$ & $33.5 \pm 5.4$ \\
\hline Duration of infertility (years) & $4.5 \pm 3.4$ & $4.3 \pm 3.3$ & $3.4 \pm 3.2$ \\
\hline Basic FSH level (IU/L) & $7.0 \pm 2.2^{b}$ & $7.0 \pm 2.3^{b}$ & $6.7 \pm 2.1$ \\
\hline BMI $\left(\mathrm{kg} / \mathrm{m}^{2}\right)$ & $22.1 \pm 2.9$ & $22.3 \pm 3.0$ & $22.0 \pm 2.9$ \\
\hline \multicolumn{4}{|l|}{ Type of infertility } \\
\hline Primary infertility & $\begin{array}{l}40.3 \%^{\mathrm{b}} \\
(622 / 1542)\end{array}$ & $\begin{array}{l}41.2 \%^{\mathrm{b}} \\
(400 / 970)\end{array}$ & $\begin{array}{l}46.6 \% \\
(718 / 1542)\end{array}$ \\
\hline Secondary infertility & $\begin{array}{l}59.7 \% \\
(920 / 1542)\end{array}$ & $\begin{array}{l}58.8 \% \\
(570 / 970)\end{array}$ & $\begin{array}{l}53.4 \% \\
(824 / 1542)\end{array}$ \\
\hline Causes of infertility & & & \\
\hline Tubal & $\begin{array}{l}57.3 \%^{\mathrm{b}} \\
(883 / 1542)\end{array}$ & $\begin{array}{l}57.0 \%^{\mathrm{c}} \\
(553 / 970)\end{array}$ & $\begin{array}{l}52.1 \% \\
(804 / 1542)\end{array}$ \\
\hline Endometriosis & $\begin{array}{l}5.4 \% \text { b } \\
(84 / 1542)\end{array}$ & $\begin{array}{l}5.5 \% \text { b } \\
(53 / 970)\end{array}$ & $\begin{array}{l}8.6 \% \\
(132 / 1542)\end{array}$ \\
\hline $\begin{array}{l}\text { Anovulation/ } \\
\text { PCOS }\end{array}$ & $\begin{array}{l}2.0 \%^{\mathrm{b}} \\
(31 / 1542)\end{array}$ & $\begin{array}{l}2.0 \%^{c} \\
(19 / 970)\end{array}$ & $\begin{array}{l}3.2 \% \\
(50 / 1542)\end{array}$ \\
\hline Male & $\begin{array}{l}14.5 \% \\
(224 / 1542)\end{array}$ & $\begin{array}{l}13.3 \% \\
(129 / 970)\end{array}$ & $\begin{array}{l}14.4 \% \\
(222 / 1542)\end{array}$ \\
\hline
\end{tabular}

Abbreviations: BMI, body mass index; PCOS, polycystic ovarian syndrome.

a Data are presented as the mean \pm SD or a percentage.

${ }^{\mathrm{b}} \mathrm{P}<.01$, compared with HBV-negative group.

${ }^{\mathrm{c}} \mathrm{P}<.05$, compared with HBV-negative group. 


\begin{tabular}{|c|c|c|c|}
\hline Group & $\begin{array}{l}\text { HBV-positive } \\
(n=1542)\end{array}$ & $\begin{array}{l}\text { HBeAg/preS1-positive } \\
(n=970)\end{array}$ & $\begin{array}{l}\text { HBV-negative } \\
(n=1542)\end{array}$ \\
\hline \multirow[t]{2}{*}{ Unexplained } & $5.3 \%$ b & $6.1 \%$ & $8.2 \%$ \\
\hline & $(81 / 1542)$ & $(59 / 970)$ & $(126 / 1542)$ \\
\hline \multirow[t]{2}{*}{ Mixed } & $15.5 \%$ & $16.2 \%$ & $13.5 \%$ \\
\hline & $(239 / 1542)$ & $(157 / 970)$ & $(208 / 1542)$ \\
\hline \multicolumn{4}{|c|}{ Abbreviations: BMI, body mass index; PCOS, polycystic ovarian syndrome. } \\
\hline \multicolumn{4}{|c|}{${ }^{a}$ Data are presented as the mean $\pm S D$ or a percentage. } \\
\hline \multicolumn{4}{|c|}{$\mathrm{b} \mathrm{P}<.01$, compared with HBV-negative group. } \\
\hline \multicolumn{4}{|c|}{${ }^{\mathrm{c}} \mathrm{P}<.05$, compared with HBV-negative group. } \\
\hline
\end{tabular}

\section{Outcomes of IVF/ICSI treatments}

The characteristics of the IVF cycles are displayed in Table 2. The peak $E_{2}$ levels in the HBV-and $\mathrm{HBeAg} / \mathrm{preS} 1$-positive groups were significantly higher than those in the HBV-negative group $(P<0.05)$. However, the ovarian responses, such as the dosage of gonadotropin used, duration of stimulation, number of oocytes retrieved, number of fertilized oocytes, cancellation rate, and number of embryos transferred per cycle, were similar among the three groups $(P>0.05)$. 
Table 2

Cycle characteristics of infertility patients according to the hepatitis B virus status of the women

\begin{tabular}{|c|c|c|c|}
\hline Group & $\begin{array}{l}\text { HBV-positive } \\
(n=1542)\end{array}$ & $\begin{array}{l}\text { HBeAg/pres1- } \\
\text { positive } \\
(n=970)\end{array}$ & $\begin{array}{l}\text { HBV-negative } \\
(n=1542)\end{array}$ \\
\hline Previous cycles & $1.2 \pm 0.5$ & $1.2 \pm 0.5$ & $1.2 \pm 0.5$ \\
\hline \multicolumn{4}{|l|}{ Protocol of $\mathrm{COH}$} \\
\hline Long protocol & $\begin{array}{l}68.1 \% \\
(1050 / 1542)\end{array}$ & $66.1 \%(641 / 970)$ & $\begin{array}{l}69.6 \% \\
(1074 / 1542)\end{array}$ \\
\hline Short protocol & $13.0 \%(201 / 1542)$ & $13.9 \%(135 / 970)$ & $11.7 \%(180 / 1542)$ \\
\hline Antagonist protocol & $11.0 \%(169 / 1542)$ & $11.6 \%(113 / 970)$ & $9.7 \%(150 / 1542)$ \\
\hline Ultra-long protocol & $7.9 \%(122 / 1542)$ & $8.4 \%(81 / 970)$ & $8.9 \%(138 / 1542)$ \\
\hline Dosage of Gn used (IU) & $2309.9 \pm 787.2$ & $2294.0 \pm 787.2$ & $2320.0 \pm 827.7$ \\
\hline Duration of stimulation (d) & $10.1 \pm 2.2$ & $10.1 \pm 2.1$ & $10.3 \pm 2.1$ \\
\hline Peak $\mathrm{E}_{2}$ level (pmol/L) & $14143.3 \pm 249.3^{b}$ & $14774.4 \pm 332.5^{c}$ & $13332.5 \pm 235.6$ \\
\hline Oocyte retrieval & $\begin{array}{l}99.8 \% \\
(1539 / 1542)\end{array}$ & $99.9 \%(969 / 970)$ & $\begin{array}{l}99.9 \% \\
(1540 / 1542)\end{array}$ \\
\hline Number of oocytes retrieved & $11.6 \pm 6.8$ & $11.8 \pm 6.9$ & $11.7 \pm 6.8$ \\
\hline \multicolumn{4}{|l|}{ Insemination method } \\
\hline IVF & $\begin{array}{l}73.7 \% \\
(1134 / 1539)\end{array}$ & $74.3 \%(720 / 969)$ & $\begin{array}{l}75.0 \% \\
(1155 / 1540)\end{array}$ \\
\hline ICSI & $26.3 \%(405 / 1539)$ & $25.7 \%(249 / 969)$ & $25.0 \%(385 / 1540)$ \\
\hline IVF fertilization rate & $72.0 \%$ & $71.8 \%$ & $72.2 \%$ \\
\hline ICSI fertilization rate & $70.0 \%$ & $67.6 \%$ & $69.0 \%$ \\
\hline Number of 2PN fertilized oocytes & $7.1 \pm 5.0$ & $7.2 \pm 5.15$ & $7.2 \pm 5.1$ \\
\hline $\begin{array}{l}\text { No oocyte pick-up or embryo } \\
\text { transfer }\end{array}$ & $6.2 \%(96 / 1542)$ & $6.7 \%(65 / 970)$ & $5.4 \%(84 / 1542)$ \\
\hline
\end{tabular}

Abbreviations: $\mathrm{COH}$, controlled ovarian hyperstimulation; ICSI, intracytoplasmic sperm injection; IVF, in vitro fertilization; 2PN, 2 pronucleus; Gn, gonadotropin.

${ }^{a}$ Data are presented as the mean $\pm S D$ or a percentage.

${ }^{b} \mathrm{P}<.01$, compared with the HBV-negative group.

${ }^{\mathrm{c}} \mathrm{P}<.05$, compared with the HBV-negative group. 


\begin{tabular}{|c|c|c|c|}
\hline Group & $\begin{array}{l}\text { HBV-positive } \\
(n=1542)\end{array}$ & $\begin{array}{l}\text { HBeAg/pres1- } \\
\text { positive } \\
(n=970)\end{array}$ & $\begin{array}{l}\text { HBV-negative } \\
(n=1542)\end{array}$ \\
\hline Freeze all embryos & $15.3 \%(236 / 1542)$ & $17.5 \%(170 / 970)$ & $15.8 \%(244 / 1542)$ \\
\hline Number of transferred embryos & $2.0 \pm 0.6$ & $2.0 \pm 0.6$ & $2.0 \pm 0.6$ \\
\hline \multicolumn{4}{|c|}{$\begin{array}{l}\text { Abbreviations: } \mathrm{COH} \text {, controlled ovarian hyperstimulation; ICSI, intracytoplasmic sperm injection; IVF, in } \\
\text { vitro fertilization; } 2 \mathrm{PN}, 2 \text { pronucleus; Gn, gonadotropin. }\end{array}$} \\
\hline \multicolumn{4}{|c|}{${ }^{a}$ Data are presented as the mean $\pm S D$ or a percentage. } \\
\hline \multicolumn{4}{|c|}{$\mathrm{b} P<.01$, compared with the HBV-negative group. } \\
\hline
\end{tabular}

\section{Outcomes of pregnancy}

IVF and ET outcomes in HBV-seropositive women were similar to those in their healthy counterparts ( $P>$ 0.05). The live birth rate and clinical pregnancy rate per ET cycle in HBsAg-seropositive or HBsAg- and $\mathrm{HBeAg} /$ preS1-seropositive women did not differ significantly from those in HBsAg-seronegative women (35.3\%, 32.8\%, and $34.3 \%$, respectively, $P>0.05$ and $43.1 \%, 40.7 \%$, and $41.6 \%$, respectively, $P>0.05$ ). Moreover, no differences were found in the implantation rate, miscarriage rate, twin pregnancy rate, birth weight, low birth weight rate or preterm rate among these three groups (Table 3). 
Table 3

Pregnancy outcomes of infertility patients according to hepatitis B virus status of the women.

\begin{tabular}{|c|c|c|c|c|}
\hline Group & $\begin{array}{l}\text { HBV positive } \\
(n=1542)\end{array}$ & $\begin{array}{l}\text { HBeAg/preS1 positive }(n= \\
970)\end{array}$ & $\begin{array}{l}\text { HBV negative } \\
(n=1542)\end{array}$ & $\begin{array}{l}P \\
\text { values }\end{array}$ \\
\hline Implantation rate & $\begin{array}{l}27.6 \% \\
(674 / 2440)\end{array}$ & $26.2 \%(389 / 1482)$ & $\begin{array}{l}26.9 \% \\
(669 / 2487)\end{array}$ & NS \\
\hline $\begin{array}{l}\text { Clinical pregnancy } \\
\text { rate }\end{array}$ & $\begin{array}{l}43.1 \% \\
(521 / 1210)\end{array}$ & $40.7 \%(299 / 735)$ & $\begin{array}{l}41.6 \% \\
(505 / 1214)\end{array}$ & NS \\
\hline Miscarriage rate & $15.9 \%(83 / 521)$ & $17.7 \%(53 / 299)$ & $15.4 \%(78 / 505)$ & NS \\
\hline Ectopic pregnancy & $2.3 \%(12 / 521)$ & $2.0 \%(6 / 299)$ & $2.4 \%(12 / 505)$ & NS \\
\hline Live birth rate & $\begin{array}{l}35.3 \% \\
(427 / 1210)\end{array}$ & $32.8 \%(241 / 735)$ & $\begin{array}{l}34.3 \% \\
(416 / 1214)\end{array}$ & NS \\
\hline Twins rate & $\begin{array}{l}24.6 \% \\
(105 / 427)\end{array}$ & $27.0 \%(65 / 241)$ & $\begin{array}{l}24.5 \% \\
(102 / 417)\end{array}$ & NS \\
\hline Total preterm & $\begin{array}{l}13.8 \% \\
(59 / 427)\end{array}$ & $12.0 \%(29 / 241)$ & $12.7 \%(53 / 417)$ & NS \\
\hline Singleton preterm & $8.7 \%(28 / 322)$ & $5.1 \%(9 / 176)$ & $8.3 \%(26 / 314)$ & NS \\
\hline Twins preterm & $29.5 \%(31 / 105)$ & $30.8 \%(20 / 65)$ & $26.5 \%(27 / 102)$ & NS \\
\hline $\begin{array}{l}\text { Birth weight of } \\
\text { singletons }\end{array}$ & $3271.1 \pm 514.8$ & $3303.0 \pm 482.6$ & $3273.3 \pm 521.5$ & NS \\
\hline Birth weight of twins & $2485.2 \pm 461.6$ & $2427.3 \pm 534.5$ & $2441.2 \pm 481.8$ & NS \\
\hline Low birth weight & $\begin{array}{l}19.4 \% \\
(103 / 532)\end{array}$ & $21.9 \%(67 / 306)$ & $\begin{array}{l}22.8 \% \\
(118 / 518)\end{array}$ & NS \\
\hline \multicolumn{5}{|c|}{ Data are presented as mean $\pm S D$ or percent } \\
\hline NS, not significant. & & & & \\
\hline
\end{tabular}

Multivariate analysis of the pregnancy outcomes adjusted for age, basic $E_{2}$ level, type of infertility, causes of infertility, peak $E_{2}$ level and $H B V$ infection status, showed no significant difference in the live birth rate between the HBV-positive or HBeAg/preS1-positive groups and the control group (adjusted OR 1.11, 95\% $\mathrm{Cl} 0.93-1.32$ and adjusted OR $1.02,95 \% \mathrm{Cl} 0.83-1.25$, respectively). Furthermore, comparison of these groups demonstrated that there were no differences in the clinical pregnancy rate (adjusted OR 1.13, 95\% $\mathrm{Cl} 0.95-1.34$ and adjusted OR $1.038,95 \% \mathrm{Cl} 0.85-1.26$, respectively) or miscarriage rate (adjusted OR $1.08,95 \% \mathrm{Cl} 0.77-1.50$ and adjusted OR $1.10,95 \% \mathrm{Cl} 0.75-1.61$, respectively).

\section{Discussion}


A paucity of data exists regarding the outcomes of ART in women with HBV infection. Lee et al. found that the ongoing pregnancy and live birth rates in HBsAg-seropositive women $(n=131)$ do not differ significantly from those in HBsAg-seronegative women [13]. Another study has reported that women who are HBsAg-seropositive $(n=77)$ have significantly lower fertilization and top-quality embryo rates than healthy controls, but the clinical pregnancy rates do not differ significantly between HBsAg-seropositive and -negative groups [10]. However, Lam et al. showed that couples with at least one HBV-seropositive partner have higher pregnancy and implantation rates in IVF ET cycles than control couples $(n=56)[14]$. Nonetheless, data are limited and all the above studies include a small number of subjects. Recently, the study by Wang et al. considered the influence of HBeAg positive, but did not exclude the influence of HBV infection in their partners on the result [17]. Therefore, it is difficult to draw a definitive conclusion. In the present study, we had a much larger sample size than that in previous studies and found no significant differences in clinical pregnancy or live birth rates between HBsAg-seropositive and -negative women. For the first time, our results reveal no significant difference in the birth weight, low birth weight rate or preterm rate of IVF/ICSI ET cycles between HBsAg-seropositive and healthy control women.

The serum HBV DNA concentration is a direct measure of viral load [18]. To date, no study has evaluated the effect of the HBV DNA concentration on IVF outcome. HBeAg $[18,19]$ and preS1 $[20,21]$ are known serum markers for active HBV replication, indicating a high HBV DNA burden. To evaluate whether the status of viral replication affects the IVF/ICSI outcome in HBV-infected women, we compared $\mathrm{HBeAg} /$ preS1-seropositive women with healthy control women. In the present study, HBeAg/preS1seropositive women had a similar live birth rate, clinical pregnancy rate, miscarriage rate, preterm rate, and low birth weight rate to uninfected women. This is the first report of a lack of association between $\mathrm{HBeAg} /$ preS1 seropositivity and pregnancy outcomes following IVF/ICSI treatment. Our retrospective cohort study found no significant increase in the miscarriage rate in HBsAg-seropositive women. However, a prior study reported a significantly increased incidence of miscarriage in pregnant women with chronic HBV infection as compared with uninfected controls [16], which is likely due to the noninclusion of certain potential confounders that may affect pregnancy. In the present investigation, all HBsAg-seropositive women undergoing IVF/ICSI ET had normal liver function and had not received any antiviral treatment. Patients with a history of recurrent spontaneous abortion, autoimmune disease, surgery or congenital defects (urological or related to the reproductive organs), long-term drug use and/or toxin or radiation exposure, and any couples who were seropositive for HCV and/or HIV were excluded from the present study.

A higher incidence of secondary infertility and tubal factor infertility was detected in HBV-infected women as compared with healthy controls. This finding is consistent with those of previous studies $[5,13,17]$. This outcome may be due to the impaired immune response that facilitates infection with common pathogens that cause pelvic inflammatory disease and tubal subfertility $[5,25]$.

The present retrospective cohort study is the largest and first to report that HBeAg/preS1 seropositivity is not associated with post-IVF/ICSI-treatment pregnancy outcomes. In our cohort study, we found that active HBV infection in women had no effect on the birth weight or preterm rate following IVF/ICSI ET.

Page 12/16 
Admittedly, our research has several limitations. Firstly, the HBV DNA serum concentration was not measured due to the retrospective nature of the study; thus, we were unable to evaluate whether viral load was correlated with pregnancy outcomes. Secondly, perinatal complications were not included and further research is required to address this subject.

In conclusion, HBV infection in women is associated with a higher risk of secondary infertility and tubal factor infertility, but has no significant impact on ovarian responses and pregnancy outcomes in HBsAgseropositive women as compared with HBsAg-seronegative women, irrespective of their serum $\mathrm{HBeAg}$ and preS1 status.

\section{Declarations}

\section{Funding:}

This work was funded by the Natural Science Foundation of China (No. 81803245 and 81873819), the Natural Science Foundation of Zhejiang Province (No. LZ15H040001 and LQ14H040003) and the National Key R\&D Program of China (No. 2018YFC1003200).

\section{Authors' contributions:}

YMZ and XLH designed the study. XLH and SW analysed the data. YWC, MYT, YLF, HMY, AXL, XJC and YCL collected the data. XLH, XM and YMZ wrote the paper. All authors read and approved the final manuscript.

\section{Compliance with ethical standards}

\section{Conflict of Interest:}

The authors declare that they have no conflict of interest.

\section{Ethical approval:}

All procedures performed in studies involving human participants were in accordance with the ethical standards of the institutional and/or national research committee and with the 1964 Helsinki Declaration and its later amendments or comparable ethical standards. The study was approved by the Ethics Committee of the Women's Hospital, Zhejiang University School of Medicine.

\section{References}

1. Poovorawan $\mathrm{Y}$, Chongsrisawat $\mathrm{V}$, Theamboonlers $\mathrm{A}$, et al. Evidence of protection against clinical and chronic hepatitis B infection 20 years after infant vaccination in a high endemicity region. J Viral Hepat. 2011;18(5):369-75.

2. https://www.who.int/en/news-room/fact-sheets/detail/hepatitis-b (accessed July 18, 2019). 
3. Chen S, Li J, Wang D, Fung H, Wong LY, Zhao L. The hepatitis B epidemic in China should receive more attention. Lancet. 2018;391(10130):1572.

4. Lutgens SP, Nelissen EC, van Loo IH, Koek GH, Derhaag JG, Dunselman GA. To do or not to do: IVF and ICSI in chronic hepatitis B virus carriers. Hum Reprod. 2009;24(11):2676-8.

5. Lao TT, Mak JSM, Li TC. Hepatitis B virus infection status and infertility causes in couples seeking fertility treatment-Indicator of impaired immune response? Am J Reprod Immunol. 2017;77(4).

6. Bertoletti A, Gehring AJ. The immune response during hepatitis B virus infection. J Gen Virol. 2006;87(Pt 6):1439-49.

7. Su FH, Chang SN, Sung FC, et al. Hepatitis B virus infection and the risk of male infertility: a population-based analysis. Fertil Steril. 2014;102(6):1677-84.

8. Oger $P$, Yazbeck $C$, Gervais A, et al. Adverse effects of hepatitis B virus on sperm motility and fertilization ability during IVF. Reprod Biomed Online. 2011;23(2):207-12.

9. Zhou XP, Hu XL, Zhu YM, Qu F, Sun SJ, Qian YL. Comparison of semen quality and outcome of assisted reproductive techniques in Chinese men with and without hepatitis B. Asian J Androl. 2011;13(3):465-9.

10. Shi L, Liu S, Zhao W, Zhou H, Ren W, Shi J. Hepatitis B virus infection reduces fertilization ability during in vitro fertilization and embryo transfer. J Med Virol. 2014;86(7):1099-104.

11. Hu XL, Zhou XP, Qian YL, Wu GY, Ye YH, Zhu YM. The presence and expression of the hepatitis $B$ virus in human oocytes and embryos. Hum Reprod. 2011; 26(7):1860-67.

12. Nie R, Jin L, Zhang H, Xu B, Chen W, Zhu G. Presence of hepatitis B virus in oocytes and embryos: a risk of hepatitis B virus transmission during in vitro fertilization. Fertil Steril. 2011;95(5):1667-71.

13. Lee VC, Ng EH, Yeung WS, Ho PC. Impact of positive hepatitis B surface antigen on the outcome of IVF treatment. Reprod Biomed Online. 2010;21(5):712-7.

14. Lam PM, Suen SH, Lao TT, Cheung LP, Leung TY, Haines C. Hepatitis B infection and outcomes of in vitro fertilization and embryo transfer treatment. Fertil Steril. 2010;93(2):480-5.

15. Tse KY, Ho LF, Lao T.The impact of maternal HBsAg carrier status on pregnancy outcomes: a casecontrol study. J Hepatol. 2005;43(5):771-5.

16. Cui AM, Cheng XY, Shao JG, et al. Maternal hepatitis B virus carrier status and pregnancy outcomes: a prospective cohort study. BMC Pregnancy Childbirth. 2016;16:87.

17. Wang L, Li L, Huang C, et al. Maternal chronic hepatitis B virus infection does not affect pregnancy outcomes in infertile patients receiving first in vitro fertilization treatment. Fertil Steril. 2019;112(2):250-7.

18. Liaw YF, Chu CM. Hepatitis B virus infection. Lancet. 2009;373(9663):582-92.

19. Lu FM, Li T, Liu S, Zhuang H. Epidemiology and prevention of hepatitis B virus infection in China. J Viral Hepat. 2010; 17 Suppl 1:4-9.

20. Petit MA, Buffello-Le Guillou D, Roche B, et al. Residual hepatitis B virus particles in liver transplant recipients receiving lamivudine: PCR quantitation of HBV DNA and ELISA of preS1 antigen. J Med 
Virol. 2001;65(3):493-504.

21. Le Guillou DB, Duclos-Vallée JC, Eberle F, Capel F, Petit MA. Evaluation of an enzyme-linked immunosorbent assay for detection and quantification of hepatitis B virus PreS1 envelope antigen in serum samples: comparison with two commercial assays for monitoring hepatitis B virus DNA. J Viral Hepat. 2000;7(5):387-92.

22. Hu XL, Feng C, Lin XH, et al. High maternal serum estradiol environment in the first trimester is associated with the increased risk of small-for-gestational-age birth. J Clin Endocrinol Metab. 2014;99(6):2217-24.

23. Wang $\mathrm{H}$, Gao H, Chi $\mathrm{H}$, et al. Effect of Levothyroxine on Miscarriage Among Women With Normal Thyroid Function and Thyroid Autoimmunity Undergoing In Vitro Fertilization and Embryo Transfer: A Randomized Clinical Trial. JAMA. 2017;318(22):2190-8.

24. Tannus S, Son WY, Gilman A, Younes G, Shavit T, Dahan MH. The role of intracytoplasmic sperm injection in non-male factor infertility in advanced maternal age. Hum Reprod. 2017;32(1):119-24.

25. Yim HJ, Lok AS. Natural history of chronic hepatitis B virus infection: what we knew in 1981 and what we know in 2005. Hepatology. 2006;43(2 Suppl 1):S173-81.

\section{Figures}




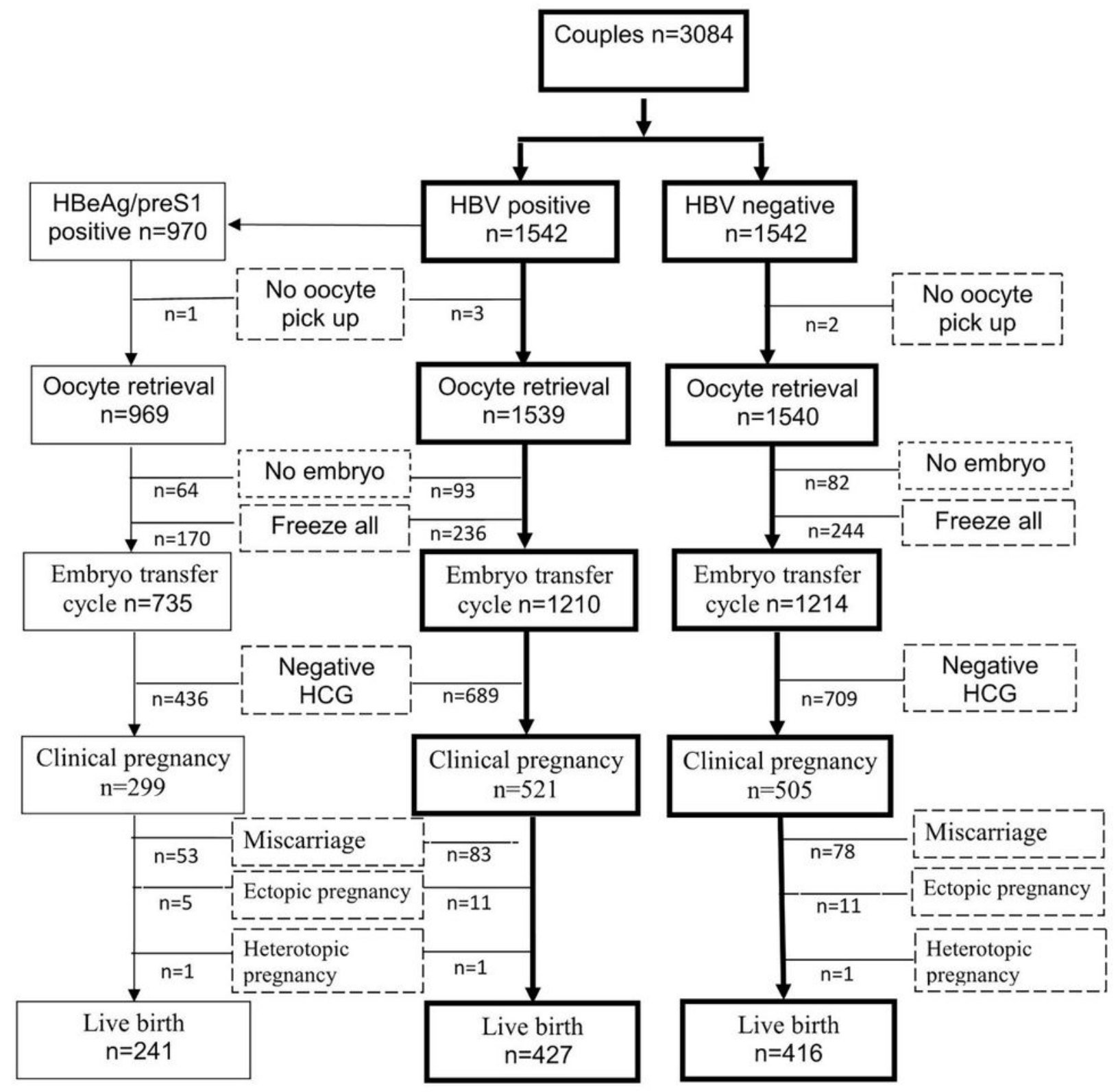

Figure 1

Patient flow through the study. 